\title{
LOCALISED DECLINES IN COLONIES OF THE SHORT-TAILED SHEARWATER: AN EXPLANATION
}

\author{
by F.I. Norman
}

(with two text-figures)

NORMAN, F.I., 1985 (31:vii): Localised declines in colonies of the short-tailed shearwater: an explanation. Pap. Proc. R. Soc. Tasm. 119:103-107.https://doi.org/10.26749/rstpp.119.103 ISSN 0080-4703. Arthur Rylah Institute for Environmental Research, Fisheries \& Wildlife Division, 123 Brown St, Heidelberg, Victoria, Australia 3084

Historical declines in local populations of the short-tailed shearwater Puffinus tenuirostris in the Furneaux Group are reviewed; particular attention is paid to information collected on Big Green Island, off Whitemark, Flinders Island. Disease, predators, and introduced stock are dismissed as ca usative agents in reported declines of colonies, as is changing vegetation. It is proposed that over-harvesting, initially of all stages and later of young, provides an explanation of such reductions, one which is demonstrated using a simple, deterministic model. Key Words: Shearwater, decline, Furneaux Group.

\section{INTRODUCTION}

Early visitors to the Bass Strait region were impressed by the large number of short-tailed shearwaters or mutton-bird Puffinus tenuirostris which they encountered (e.g. Flinders 1814, Davies 1846, Gabriel 1912). However, decreases in areas occupied by breeding colonies on some islands were reported by later authors and various causative agents proposed. The evidence for a decline on one such island is examined in this note and an explanation proposed for the changed nature of the colonies' distribution on the island, and elsewhere.

Big Green Island, Furneaux Group, Tasmania has been described in some detail elsewhere (Norman 1966, 1970a). The island has a long history (since about 1830) of intensive sheepgrazing, with numbers occasionally exceeding 1000 . This stocking rate averages about 8 sheep/ha over the island, but is effectively greater when allowance is made for the unvegetated areas of granite which extend over about $50 \%$ of the island. During occupancy of the island, rabbits Oryctolagus cuniculus were introduced and eliminated, and the vegetation has been changed from a variously reported complex of grasses, thistles and nettles, mallows and saltbush to one typically of a coastal tussock belt (Stipa teretifolia and Poa poiformis) backed by a predominantly exotic grassland (including Holcus lanatus, Hordeum leporinum Bromus spp., and Trifolium spp.) maintained by sheep. When Davies (1846) visited Green Island he considered that it was all burrowed, Thomas (1861) found guano in soil samples taken at the northern end, and Backhouse and Tylor (1862) reported a dense colony on the island's southern end. Contemporary newspapers (e.g. Launceston Examiner 26 May 1883) mentioned that colonies occupied much of the island. However, by 1893 "the place was a sheep farm, and real mutton was growing where thousands of Mutton Birds used annually to flourish" (Campbell 1900). Montgomery (1891, 1900) also noted with concern the decline in numbers and predicted disappearance of the ind ustrial harvest, although at about the same time (Montgomery, 1898) he had considered it adequately protected. Lord (1908) reported that colonies on the island had decreased to the point that there was only one remaining.

Such historical accounts clearly indica te that shearwater colonies were considered to have occupied much of Big Green Island in the past. To substantiate such statements, and to determine approximate earlier distributions 22 transects were established in 1965 and 1966, across parts of the island not now burrowed by breeding shearwaters, and 270 holes (depths varied according to substrate) dug at intervals. The presence of shearwater bones in 94 of the sample holes was taken as evidence that nesting previously took place in those areas. Comparison of transect information and current (i.e. 1965-1968) colony distribution (fig. 1) indicates that breeding colonies were formerly more extensive, particularly along the eastern slopes of the island. Surface and sub-surface bedrock would have influenced the extent of local burrowing, as it does still. 


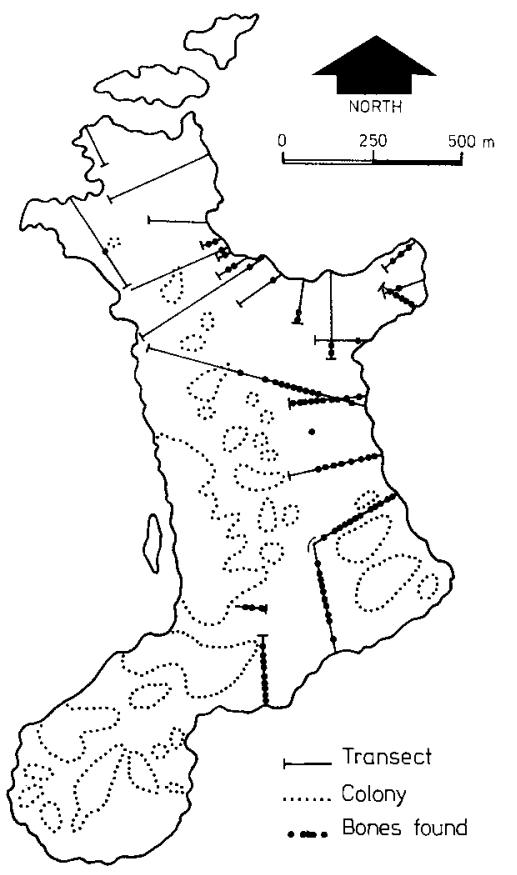

FIG 1 - Distribution of colonies of the short-tailed shearwater on Big Green Island, 1965-1968; the location of earlier colonies as evidenced by bones.

\section{CAUSES OF DECLINE}

What then caused the decline of breeding shearwaters on Big Green Island, and perhaps those reported (Montgomery, 1891, Lord 1908, Baker 1909) elsewhere in the Furneaux Group? Diseases, such as 'limy-bird' or ornithosis, or other, do not appear to have been extensively reported and are certainly not now of major, or even continuing, importance. Starvation may affect birds returning to breeding grounds in some years, occasionally in large numbers, and since breeding birds are involved there may be temporary but localised effects, as there would if food was restricted during the breeding season itself. Local breeding success may be reduced substantially in some years following heavy rains (see Serventy 1961, 1967, 1974, Serventy et al. 1971 for further details). Potential native mammalian predators, such as the larger dasyurids, have not been recorded from Green Island or from other small islands in the Furneaux Group (Hope 1973), and snakes (tiger snake Notechis scutatus or copperhead Austrelaps superba), which might take eggs or small young shearwaters (Serventy et al. 1971), were early removed (Brownrigg 1872). Avian predators such as the Pacific gull Larus pacificus are of little consequence to local populations (Norman 1970b), there are no records of feral cats on the island, and the introduced black rat Rattus rattus is not considered to play a role in reducing bird numbers at any stage (Norman 1970c).

Earlier commentators (Thomas 1861, Campbell 1900, Lord 1908, Littler 1910) imputed or stated that sheep were responsible, in part or entirely, for the destruction of the island's colonies. Serventy et al. (1971) considered that stock trampled and consolidated ground, thus reducing burrow concentration. However, Norman (1970a) found that sheep did not prevent utilisation of existing colonies on Big Green Island, nor did they decrease breeding success, and artificial burrows were not in demand. Burrow collapses were attributable, during the breeding season, to the birds themselves and occurred in the absence of sheep, as indeed they do elsewhere (Harris \& Norman 1981). Long term maintenance of burrows may be related to the type of root system of the covering vegetation. On Green Island, eroding areas of burrows associated with unstable vegetation have not developed, presumably because of the close, dense cover provided by the shallow-rooted, predominantly introduced plant species. The exotic grassland, maintained by grazing sheep (and by infrequent supplementary sowing) did not prevent expansion of breeding colonies. Indeed, on Green Island as in other colonies the shearwater was successfully using a reas dominated by exotic vegetation (Harris \& Norman 198I, Norman 1970a). Such factors are not therefore considered to have materially affected the size of the breeding population of shearwaters on Big Green Island.

Cott (1953) and others have implicated overharvesting in the decline of the mutton-bird and, despite the views of Serventy et al. (1971) that the taking of birds and their eggs were of little consequence, it is appropriate to review some historical aspects of the industry, before examining the direct effects of harvesting.

When Davies (1846) discussed Big Green Island and its shearwaters, he noted that aboriginals were taking large numbers of eggs from it, quite apart from the young harvested later in the 'birding' season. Extrapolation from the details provided by Davies may suggest that over 70,000 eggs were taken but such collections would have been impossible in the mid-1960s when the island's population was estimated at about 10,000 (Norman 1970b). Nevertheless, some 300,000 eggs were removed from nearby Chappell Island in 1864 when the market was "chiefly confined to eggs, fat, oil and feathers (and) comparatively few birds being salted by market" (Lord 1908). Even in 1908 Lord considered that over $1,000,000$ birds had been 
taken from the Furneaux Group. He noted that eggs and adults were still being taken, estimated recent minimum annual harvests, and felt that "it would be remarkable if the supply did not eventually run out". On Preservation Island harvests were similarly large. Thus Backhouse and Tylor (1862) stated that 2-3 tons were being collected annually, and Elwes (1859) had earlier thought that about 56,000 birds were required to produce a ton of feathers. On Big Green Island itself a birder was taking 15-20,000 shearwaters annually in the late $1870 \mathrm{~s}$ but apparently found it difficult to get 450 birds in 1907 (Lord 1908). In about 1892 some 2,500 young birds were being taken daily, "for several weeks", to be boiled down for fat prod uction (Legge 1893). There is therefore every reason to assume that on an inhabited island, such as Big Green Island, exploitation rates were high and resembled those pertaining in neighbouring, seasonally-birded colonies.

\section{EXPLOITATION MODELS}

Exploitation of a theoretical shearwater population may be examined using data provided by Serventy (1967, 1974), Norman (1970a) and Serventy and Curry (1984), together with information from related species. Such a population may be generated and subjected to varying conditions. Here, a hypothetical population is investigated using a deterministic model in which the following assumptions apply:

i) the population starts with 200 breeding adults aged 6 , a foundation group which settled an otherwise unoccupied nesting area;

ii) birds first breed at 6 years of age. Serventy (1967) gave a mean figure of 5.9 years for both sexes and Serventy and Curry (1984) note that some breeding started at 5 years for both males and females and ranged to over 10 years;

iii) pre-breeding birds have an average annual mor tality of $15.5 \%$. This approximates the data of Serventy $(1967,1974)$, who indicated $63 \%$ for the $0-3$ year group, and $56 \%$ for the 3-5 year olds. Serventy and Curry (1984) found that $35 \%$ of returning young went on to breed in the natal colony, and some $42 \%$ of those fledging were recaptured;

iv) adult, breeding birds have an annual mortality of $7 \%$. Farner (1962) gave a minimum of $91 \%$ survival and suggested that it might be $95 \%$ in a stable population;

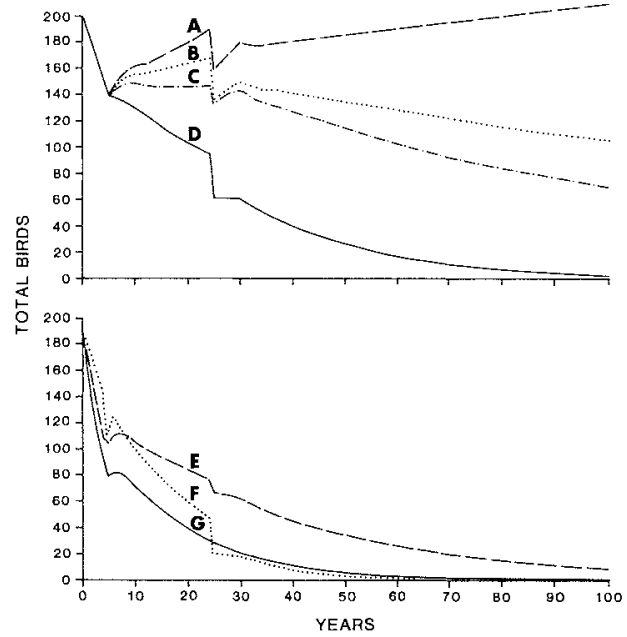

FIG 2 - Comparison of unharvested, theoretical population (A) with populations subjected to young harvested at $10 \%(\mathrm{~B})$, at $20 \%(\mathrm{C})$, at $50 \%$ (D); adults harvested at $10 \%(\mathrm{E})$, adults harvested at $5 \%(\mathrm{~F})$; young cropped at $50 \%$, adults at $1 \%$, and eggs at $35 \%(G)$. Such additional mortalities are imposed on the other model parameters given in the text.

v) all birds have a potential life expectancy of 30 years. Harris (1966) gave 29 years as the maximum age reached by Puffinus puffinus and Serventy (1974) considered that the mean expectation of life in $P$. tenuirostris was about 21 years. More recently Serventy and Curry (1984) suggested that generation time exceeded 30 years. (In the present model, the instant elimination of birds in the ultimate age group results in a population drop at $24-25$ years. This trend may be minimised by the introduction of other age groups in the pioneering colony or the insertion of variously-aged immigrants, as may the initial decline due to the absence of breeding birds entering the model population);

vi) one egg per pair of adults is laid each season. Of these $70 \%$ hatch and $68 \%$ of the young produced survive to fledge and enter the pre-breeding group, thus approximating to results obtained on Green Island between 1965 and 1968 (Norman 1970a). (These data, when used in concert with those for the pre-breeding group, suggest that the adult mortality rate should be slightly higher, for a stable population, to balance the influx of young produced. Though accepted in 
this model, presumably all parameters require further refinement. Indeed, $P$. Currypers. comm. suggests that both the adult mortality rate and that of the prebreeding group should be reduced. $\mathrm{He}$ notes too that age-dependent mortality is demonstrable in this species).

In this model population it is assumed that emigration of nesting birds to breed elsewhere exists (see Serventy 1967), of ten at a relatively high level (Serventy \& Curry 1984), but is balanced by immigration from other sites. There is neither senility nor sexual discrimination in this population which expands slowly after several generations (A in fig. 2), reaching 209 birds after 100 years.

\section{RESULTS AND DISCUSSION}

From studies elsewhere in the Furneaux Group, Serventy $(1961,1974)$ considered that birders took between 19.6 and $63.4 \%$ of the young produced in commercially-operated colonies, though he did suggest that it might be higher. Thus the annual population of fledging birds in the hypothetical population has been cropped at 10,20 and $50 \%$ and compared with the unharvested population (fig. 2). Clearly cropping of young birds affects the population growth, and at around $10 \%$ the population declines (to reach $52.6 \%$ of its original size in 100 years) becoming more sapidly extinct when harvesting approaches $50 \%$. Again, if breeding adults are taken, then the model population declines and becomes extinct. A $1 \%$ increase in this model reduces the population to 8 birds after 100 years. Indeed, increases in the annual adult mortality presents perhaps the major influence on this model population's size, as it does in natural populations of other sea birds (Nelson 1980). Removal of eggs, thereby decreasing the effective hatching rate, does not affect the population to the same extent when applied in the absence of other harvesting. However, the cumulative effect of collecting eggs and harvesting adults and young is catastrophic. Since the cropping approximations used in the model are conservative by comparison with recent estimates for the harvesting of young birds alone, (Skira and Wapstra (1980) estimated that between 83.2 and $96.3 \%$ of the fledging birds were harvested, during licensed seasons, in some heavily-worked colonies), and since no losses are attributed to disturbance of adults incubating eggs or rearing young, it is not surprising that declines in the breeding population occurred on Big Green Island, and on other islands in the Furneaux Group.

Though it is improbable that complete trade totals for this species will be reconstructed, and though totals taken for local, private consumption will remain unknown, it is nevertheless clear that enormous numbers were harvested in the Furneaux Group. Whilst Lord (1908) estimated the magnitude of the harvest of the 1908 season and gave earlier details, the harvesting of adults, young and eggs had begun years before. Certainly at Green Island, aboriginals from Flinders Island were gathering substantial amounts of eggs and birds by the 1830 s (Davies 1846, Brownrigg 1872). If over-harvesting was initiated then, and was intensified when the island was permanently occupied, then there is little doubt that this would result in declines in the numbers of birds breeding by 1893 when Campbell (1900) reported on the state of the colonies. If the birder operating in the 1870s (Lord 1908) was taking $50 \%$ of the population of young, then the breeding population on the island would have exceeded 125,000; by 1907, again using model parameters, it would have declined to about 4,000 . Increasing restrictions placed upon those involved in the taking of birds privately or for trade in the more limited seasons (including the banning of collecting eggs and adults) resulted in the harvest being centred around young birds. Although the take from the Furneaux Group still exceeded 900,000 in 1930 , totals have generally decreased since (Naarding 1980).

Reduction of cropping of adults, young and eggs, and the eventual decline of harvesting of young would alter population expansion. In this regard it is of note that Sharland (1956) reported that the numbers and colonies of shearwater showed increases in the early 1940s and Serventy (1974) considered that the expansion took place some what earlier and that it is still continuing. Such expansion may of course have been assisted by the re moval of native scrub, which occurred on many islands in the Furneaux Group, and its replacement by a ground-cover more amenable to burrowing birds. It is not, therefore, necessary to involve grazing stock, particularly sheep, as the causative agent in localised population declines of $P$. tenuirostris; rather that over-harvesting of various stages of the shearwater's life provides an adequate explanation. Such a proposition was alluded to years ago by Baker (1909), Belcher (1914) and others, and it has been repeated recently by Skira and Wapstra (1980) with respect to heavily-harvested colonies in Tasmania. Indeed the latter authors noted that the influence of increased harvesting, particularly at non-commercial colonies, may be recognised only some time later when the population decline "could be sudden and dramatic". Early birders, knowing little of the ecology of the species and nothing of its delayed maturity and low adult mortality, would have been unaware that their practices could lead to the destruction of the resource itself. 


\section{ACKNOWLEDGEMENTS}

The model used here was initially developed by $M$. Legge, and later modified by M. Mobley and L. Watson. To these I express my gratitude as I do to Mr P. Curry, Department of Agriculture, Western Australia, for his comments on the draft manuscript. Field work on Big Green Island was supported by the Frank M. Chapman Memorial Fund and the M.A. Ingram Trust.

Mr. H.B. Blundstone (Whitemark) provided every assistance and hospitality in travel to and from the island, and accommodation on it.

\section{REFERENCES}

BACK HOUSE, J. \& TYLOR, C., 1862: THE LIFE AND LABOURS OF GEORGE WASHINGTON WALKER. Bennet, London.

BAKER, H., 1909: Mutton-birds of the Furneaux Group. Pap. Proc. R. Soc. Tasm. (1908): vii.

BELCHER, C.F., 1914: THE BIRDS OF THE DIS TRICT OF GEELONG. AUSTRALIA. Griffiths, Geelong.

BROWNRIGG, M.B., 1872: THE CRUISE OF THE FREA $K$. Turner, Launceston.

CAMPBELL, A.J., 1900: NESTS AND EGGS OF AUSTRALIAN BIRDS. Pawson and Brailsford, Sheffield.

COTT, H.B., 1953: The exploitation of wild birds for their eggs. Ibis 96: 409-449.

DAVIES, R.H., 1846: Some account of the habits and natural history of the sooty petrel (mutton bird). Tas. J. Nat. Sci. 2: 13-16

ELWES, R. 1859: Note on the breeding and mode of capture of the short-tailed petrel, or mutton-bird (Puffinus obscurus), in the islands of Bass's Strait. Ibis 1: 397-399.

FARNER, D.S. 1962: Survival in Puffinus tenuirostris In PALMER, R.S. (Ed.): HANDBOOK OF NORTHERN AMERICAN BIRDS, (Vol. 1). Yale University Press, New Haven.

FLINDERS, M., 1814: A VOYAGE TO TERRA AUSTRALIS ... . G. and W. Nichol, London.

GABRIEL, J., 1912: Further notes on the mutton-birds of Bass Strait. Victorian Nat. 28: 206-212.

HARRIS, M.P., 1966: Age of return to the colony, age of breeding and adult survival of Manx shearwaters. Bird Study 13: 84-95.

HARRIS, M.P. \& NORMAN, F.I., 1981: Distribution and status of coastal colonies of seabirds in Victoria. Mem. Nat. Mus. Vict. 42: 89-106.

HOPE, J.H., 1973: Mammals of the Bass Strait islands. Proc. R. Soc. Vict. 85: 163-196.

LEGGE, W.V., 1893: [Correspondence]. Pap. Proc. R. Soc. Tasm. (1892): $i x-x$

LITTLER, F.M., 1910: A HANDBOOK OF THE BIRDS OF TASMANIA AND ITS DEPENDENCIES. Launceston.
LORD, J.E.C., 1908: Furneaux Islands: report upon the state of the islands ... . Parl. Paper. Tasmania, no. 57.

MONTGOMERY, H.H., 1891: Some account of the mutton birds or sooty petrels (Nectris brevicaudus) as seen ... during a visit to the locality in March 1891. Pap. Proc. R. Soc. Tasm. (1891): $1-9$.

MONTGOMERY, H.H., 1898: On the habits of the mutton-bird of Bass Strait, Australia (Puffinus tenuirostris). Ibis 4: 209-215.

MONTGOMERY, H.H., 1900: The mutton bird ind ustry. Pap. Proc. R. Soc. Tasm. (1898-1899): xv.

NAARDING, J.A. 1980: Study of the Short-tailed Shearwater Puffinus tenuirostris in Tasmania. National Parks and Wild life Service, Tasmania.

NELSON, B., 1980: SEABIRDS: THEIR BIOLOGY AND ECOLOG Y. Hamlyn, London.

NORMAN, F.I., 1966: A note on the vegetation of Big Green lsland, Furneaux Group, Tasmania. Victorian Nat. 83: 294-299.

NORMAN, F.1., 1970a: The effects of sheep on the breeding success and habitat of the Short-tailed Shearwater, Puffinus tenuirostris (Temminck). Aust. J. Zool. 18: 215-229.

NORMAN, F.I. 1970b: Notes on the birds of Big Green Island, Furneaux Group, Tasmania 1965-1968. Victorian Nat. 87: 131-141.

NORMAN, F.1. 1970c: Food preferences of an insular population of Rattus rattus. J. Zool., Lond. 162: 493-503.

SERVENTY, D.L., 1961: The banding programme on Puffinus tenuirostris (Temminck). II. Second report. CSIRO Wildl. Res. 6: 42-55.

SERVENTY, D.L., 1967: Aspects of the population ecology of the Short-tailed Shearwater Puffinus tenuirostris. Proc. I4th Int. Orn. Congr. (1967): $165-190$.

SERVENTY, D.L., 1974: The biology behind the mutton-bird ind ustry. Pap. Proc. R. Soc. Tasm. 207: 1-9.

SER VENTY, D.L. \& CURRY, P.J., 1984: Observations on colony size, breeding success, recruitment and inter-colony dispersal in a Tasmanian colony of Short-tailed Shearwaters Puffinus tenuirostris over a 30-year period. Emu 84:71-79.

SERVENTY, D.L., SERVENTY, V. \& WARHAM, J., 1971: A HANDBOOK OF AUSTRALIAN SEA-BIRDS. A.H. \& A.W. Reed, Sydney.

SHARLAND, M., 1956: Population rise in two seabirds. Emu 56: 75-79.

SKIRA, I.J. \& WAPSTRA, J.E., 1980: Occupation of burrows as a means of estimating the harvest of Short-tailed Shearwaters in Tasmania. Emu 80: 233-238.

THOMAS, J., 1861: [Unpublished survey of Big Green Island, in Survey diagrams, Furneaux Group. vol. 4, folio 58]. Surveyor-General's Department, Hobart.

(accepted Dec. 6, 1984) 